\title{
Suitability of Metakaolin in Concrete
}

\author{
Sonal Shah and S. N. Desai
}

\begin{abstract}
Profound research work on the use of different types of clays in mortar and in concrete is done by researchers. There is a general and unanimous conclusion among the researchers that of all the clay available on earth's crust, Metakaolin (produced from kaolin clay) is a material with maximum pozzolanic reactivity. This pozzolanic reactivity of Metakaolin, depends on its physical characteristics like specific surface area, its amorphousness, the particle size distribution; and these physical attributes in turn depend upon process of dehydroxylation $i$. e. the degree at which the clay is dehydroxylated and the residence time. The usage of metakaolin in concrete and cement industry requires a good understanding of how these factors affect the strength and durability of concrete when added to it. This paper explains the working of Metakaolin, its hydration mechanism with cement and how it alters the microstructure and enhances the durability and mechanical strength of the concrete when added in concrete which is pivotal to utilize the potential of metakaolin for the research work in this industry.
\end{abstract}

Index Terms-Amorphousness, dehydroxylation, durability, hydration mechanism, pozzolanicity.

\section{INTRODUCTION}

Pozzolanic materials or supplementary cementitous materials (SCM) like fly ash, rice husk, ggbs (ground granulated blast furnace slag) and silica fume are used as cement replacement to produce high performance concrete. Metakaolin which is a relatively new material in concrete industry is effective in increasing strength, reducing sulphate attack and improving the porosity of concrete. These pozzolanic materials when added in concrete, change the microstructure of the concrete and the chemistry of the hydration reaction of cement by reacting with the released calcium hydroxide/ portlandite $(\mathrm{CH})$ (a non strength contributing compound and may leach out affecting the durability negatively), to form C-S-H gel which is the main strength giving compound resulting in contributing to the strength enhancement, reduced porosity and therefore improved durability of the concrete.[1] The use of metakaolin (MK) as a supplementary cementing material (SCM) has gained wide application in the production of high strength and high performance concrete.[2] Like other pozzolanic admixtures like fly ash, ggbs, rice husk, silica fume its contribution is mainly related to chemical activity (usually pozzolanic) and physical activity (microfiller and hydration

Manuscript received November 6, 2017; revised May 2, 2018.

Sonal Shah is with Sardar Vallabhbhai National Institute of Technology, Surat, India 395007 (e-mail: sonalshahtripathi@ boulder.gmail.com).

Satish Desai is with Applied Mechanics Department, Sardar Vallabhbhai National Institute of Technology, Surat, India 395007 (e-mail: snd_02@hotmail.com.). acceleration effect) for the cement hydration. But there are significant differences between MK and other pozzolanic additives which set it apart from these pozzolanic materials and make it a subject of interest to the researchers. Metakaolin is produced by calcinations of kaolin clay under controlled temperature. Thus, unlike other pozzolanic materials which are the byproduct of some other primary product, metakaolin is a manufactured product and its dehydroxylation process affects its physical characteristics like specific surface area, particle size distribution, its amorphousness which are the factors responsible for the pozzolanicity of a pozzolanic material. Thus, the usage of MK in concrete demands a good understanding of impact that these factors have on the hydration mechanism and the microstructure of the concrete.

\section{MetakaOlin}

Metakaolin consists of 50-55\% silica and 40-45\% alumina. [3], [4]. It is obtained by calcining kaolin clay. Kaolin is a layered silicate mineral, with one tetrahedral sheet of silica (SiO4) linked through oxygen atoms to one octahedral sheet of alumina (AlO6) octahedra. Kaolin clay $(\mathrm{Al} 2 \mathrm{O} 3 \cdot 2 \mathrm{SiO} 2 \cdot 2 \mathrm{H} 2 \mathrm{O})$ when calcined at appropriate temp of $650^{\circ}-900^{\circ}$ in a controlled way, its crystalline structure undergoes reorganization and it is transformed into a highly reactive amorphous form called Metakaolin, a pozzolanic material with a very high pozzolanicity. The formula for metakaolin is $\mathrm{Al} 2 \mathrm{O} 3 \cdot 2 \mathrm{SiO} 2$ (AS2). It is established that the silica layer remains intact and there is rearrangement only in its $\mathrm{Al}$ layers. This occurs as most of the $\mathrm{OH}$ ions are bonded with $\mathrm{Al}$ sheets and hence calcining of clay would lead to the removal of $\mathrm{OH}$ ions from $\mathrm{Al}$ layers and hence the major rearrangement is seen only in $\mathrm{Al}$ ions. [5]

In order to produce metakaolin for use as a supplementary cementitious material or pozzolana, nearly complete de-hydroxylation must be reached without overheating, i.e., thoroughly roasted but not burnt. Perfect temperature produces a disordered, amorphous state that is highly pozzolanic. Exposing it to thermal temperature beyond certain point will cause sintering and formation of mullite which is a dead burnt and a non-reactive substance. Thus, it means that the reactivity of metakaolin is much dependent upon its process of de-hydroxyaltion.

\section{A. Structural Transformations of Kaolin under Heat Treatment [6]}

Kaolinite group clays undergo a series of phase transformations upon thermal treatment in air at atmospheric pressure. The following are the phases of kaolin when heated.

\section{B. Drying}

Below $100{ }^{\circ} \mathrm{C}$, exposure to dry air will slowly remove 
liquid water from the kaolin. The end state for this transformation is referred to as "leather dry". Between $100^{\circ} \mathrm{C}$ and about $550^{\circ} \mathrm{C}$, any remaining liquid water is expelled from kaolinite. The end state for this transformation is referred to as "bone dry". Throughout this temperature range, the expulsion of water is reversible: if the kaolin is exposed to liquid water, it will be reabsorbed and disintegrate into its fine particulate form. Subsequent transformations are not reversible, and represent permanent chemical changes.

\section{Metakaolin}

Endothermic dehydration of kaolinite begins at $550^{\circ}-$ $600{ }^{\circ} \mathrm{C}$ producing disordered metakaolin, but continuous hydroxyl loss is observed up to $900^{\circ} \mathrm{C}$. Although historically there was much disagreement concerning the nature of the metakaolin phase, extensive research has led to a general consensus that metakaolin is not a simple mixture of amorphous silica ( $\mathrm{SiO} 2)$ and alumina (Al2O3), but rather a complex amorphous structure that retains some longer range order (but not strictly crystalline) due to stacking of its hexagonal layers.

$\mathrm{Al}_{2} \mathrm{Si}_{2} \mathrm{O}_{5}(\mathrm{OH})_{4} \rightarrow \mathrm{Al}_{2} \mathrm{Si}_{2} \mathrm{O}_{7}+2 \mathrm{H}_{2} \mathrm{O}$.

\section{Spinel}

Recrystallistion of the amorphous metakaolin form takes place on further heating to $925-950{ }^{\circ} \mathrm{C}$ and converts metakaolin to an aluminium-silicon spinel which is sometimes also referred to as a gamma-alumina type structure:

$$
\mathrm{Al}_{2} \mathrm{Si}_{2} \mathrm{O}_{7} \rightarrow \mathrm{Si}_{3} \mathrm{Al}_{4} \mathrm{O}_{12}+\mathrm{SiO}_{2}
$$

\section{E. Platelet mullite}

Upon calcination above $1050{ }^{\circ} \mathrm{C}$, the spinel phase nucleates and transforms to platelet mullite and highly crystalline cristobalite:

$\mathrm{Si}_{3} \mathrm{Al}_{4} \mathrm{O}_{12} \rightarrow 2\left(3 \mathrm{Al}_{2} \mathrm{O}_{3} \cdot 2 \mathrm{SiO}_{2}\right)+5 \mathrm{SiO}_{2}$.

\section{F. Needle mullite}

Finally, at $1400{ }^{\circ} \mathrm{C}$ the "needle" form of mullite appears, offering substantial increases in structural strength and heat resistance. This is a structural but not chemical transformation.

\section{THE EFFECT OF AdDition OF POZZOLANS}

Replacement of cement by mineral admixtures influences the properties of cement, mortar and concrete. The impact of adding pozzolans on the mechanical and transport properties of concrete is attributed to two effects 1) physical effect and 2) chemical effect.

Physical effect: pozzolans affect the concrete physically in three ways i) dilution effect, ii) filler effect and iii) heterogeneous surface nucleation and chemical effect: the chemical reaction with the hydrates $(\mathrm{CH})$ of the cement and forming $\mathrm{CSH}$ gel.

\section{A. Physical Behaviour of Mineral Admixtures in Cementitious Materials[7]}

Three main physical effects are observed during hydration process when mineral admixtures are used in concrete. Two of these effects, i.e. cement dilution and modification of the particle size distribution-the filler effect, are the direct consequences of replacement of cement by a mineral powder. The third effect -the heterogeneous nucleation, becomes significant when the size of the particle is extremely small and has large surface area.

\section{1) Dilution (substitution) effect}

The addition of mineral admixture if they were physically and chemically inert would reduce the strength of concrete in proportion to the replacement level. This effect is called dilution effect. Dilution effect reduces the strength of concrete.

\section{2) Filler effect}

Finely divided mineral particles when added to cement they fill the intergranular gap between the cement grains and improve the compactness of concrete and would produce more efficient packing at the cement paste aggregate particle interface, reduce the amount of bleeding and produce a denser, more homogenous narrow transition zone. Thus, relative to no cement replacement, partial replacement by ultra fine solids results in a reduction in strength of pastes (due to the dilution effect) but an increase in the strength of concrete when mineral admixtures are used in cementitious materials, this is termed as filler effect.

\section{3) Heterogeneous nucleation}

It is a physical process leading to a chemical activation of the hydration of cement. It is related to the nucleation of hydrates on foreign mineral particles, which catalyzes the nucleation process by reducing the energy barrier. Qualitatively, if the surface of the solid substrate matches well with the crystal, the interfacial energy between the two solids is smaller than the interfacial energy between the crystal and the solution, and nucleation may take place at a lower saturation ratio on a solid substrate surface than in pore solution without mineral admixture. The mineral powder used does not have to be reactive in itself since its primary function is to provide nucleation sites to the hydrates, to foster nucleation. (Figure 1). Two factors important on which heterogeneous nucleation depends are: (a)the amount of mineral admixture used, since the probability for nucleation sites to be near cement particles increases with the amount of foreign particles; (b) the affinity of the mineral powder for cement hydrates which is related to the nature of the mineral used.

One hypothesis explaining the enhancement of cement hydration is that the thickness of the hydrated layer formed around cement grains is reduced when mineral particles are present. The hydration of the anhydrous part, which rapidly becomes related to diffusion phenomena, is then facilitated. Consequently, if the particles of mineral admixture are sufficiently fine and near the cement particles, this leads to an enhancement of cement hydration.

\section{B. Chemical Behaviour of Mineral Admixtures in Cementitious Materials}

The mineral admixture apart from physically altering the microstructure of cement paste also reacts chemically with the products of cement hydrates to form strength giving compounds thus has chemical potential to improves the microstructure of cement matrix by reducing the pores and 
enhancing the strength and durability of concrete.

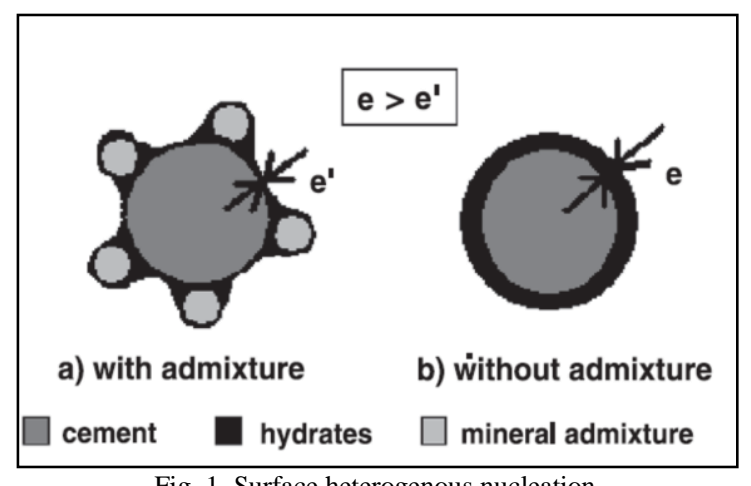

Fig. 1. Surface heterogenous nucleation.

Pozzolanic activity, which modifies the chemical equilibrium of ionic species in pore solutions, usually occurs at a later stage of hydration. However, they can affect the short-term hydration of cement. This can occur for very active admixtures, when the rapid dissolution of silica leads to immediate consumption of calcium hydroxide. It depends on the composition and solubility of the mineral admixtures and it has been shown that some materials, like colloidal silica can modify the hydration kinetics of cement in the short term by chemical processes.

\section{Factors Affecting the Reactivity of Pozzolans}

The following are the major factors that affect the reactivity of Pozzolans

1) Chemical composition $\left(\mathrm{SiO}_{2}+\mathrm{Al}_{2} \mathrm{O}_{3}+\mathrm{Fe}_{2} \mathrm{O}_{3}\right)$ content

2) The degree of amourpheness of its structure

3) Fineness of its particles

D. $\mathrm{SiO}_{2}+\mathrm{Al}_{2} \mathrm{O}_{3}+\mathrm{Fe}_{2} \mathrm{O}_{3}$ content

The greater amount of these, the greater its activity.ASTM C 618 \& TS 25 stipulates $\min$ "SiO2+Al2O3+Fe2O3" for natural pozzolans $>70 \%$. For different pozzolanas this content is as follows which would affect its pozzolanicity.

\section{E. The degree of Amorphousness of its Structure}

For chemical reaction between the cement paste and pozzolana the pozzolans must be amorphous. Volcanic ash, volcanic tuff, fly ash, silica fume are all amorphous by nature. Clays contain high amounts of silica $\&$ alumina but have a crystallic structure. They do not possess pozzolanic activity. However, by heat treatment, such as calcining $\sim 700-900^{\circ} \mathrm{C}$ crystallic structure is destroyed \& a quasi-amorphous structure is obtained. Clay does not possess pozzolanic property. Burned clay possess pozzolanic property. Blast furnace slag contain high amounts of silica, alumina $\&$ lime.

\section{F. Fineness}

Pozzolanic activity increases as fineness increases. Volcanic ash, rice husk ash, fly ash, condensed silica fume are obtained in finely divided form. Volcanic tuff, granulated blast furnace slag \& burned clay must be ground.

\section{Metakaolin-Cement HydRation Mechanism}

Metakaolin reacts with calcium hydroxide $(\mathrm{CH})$ that is liberated during the cement hydration process in presence of water to form C-S-H gel. Metakaolin also contains alumina in range of $40-45 \%$ which on reaction produce additional alumina phases some of which are crystalline. These phases are C4AH13, C2ASH8 (stratlingite), C3AH6 (hydrogarnet) (Wild et al., 1997).

The following are the hydrated products from metakaolin and cement hydration process have been shown by Murat (Wild \& Khatib, 1997).

$$
\begin{aligned}
& \mathrm{AS}_{2}+6 \mathrm{CH}+9 \mathrm{H}=\mathrm{C}_{4} \mathrm{AH}_{13}+2 \mathrm{CSH} \\
& \mathrm{AS}_{2}+5 \mathrm{CH}+3 \mathrm{H}=\mathrm{C}_{3} \mathrm{AH}_{6}+2 \mathrm{CSH} \\
& \mathrm{AS}_{2}+3 \mathrm{CH}+6 \mathrm{H}=\mathrm{C}_{2} \mathrm{ASH}_{8}+\mathrm{CSH}
\end{aligned}
$$

where, AS2 is $\mathrm{Al} 2 \mathrm{O} 3 \cdot 2 \mathrm{SiO} 2, \mathrm{H}$ is $\mathrm{H} 2 \mathrm{O}, \mathrm{CH}$ is calcium hydroxide.

Finely divided pozzolanic materials when added to cement has an immediate dilution effect (i.e. a reduction in strength in proportion to the replacement level). As they themselves do not posses any hydraulic properties, they tend not to contribute to any strength. But the reduction in strength is not directly proportional, to the substitution amount. That means apart from dilution effect there has to be some another effect which plays a role in strength development. The decrease in the rate of hydration is not directly proportional to the \% substitution. [8]. It's clearly understood that the finely divided particles act as inert material and accelerate hydration of cement by acting as sites of nucleation for the hydrated products of the cement which in turn contributes to the strength. The partial substitution of cement by metakaolin allows for increasing compressive strength of cement pastes, mortars (concretes) along with reducing their porosity and permeability making the microstructure more dense and compact (Poon et al., 2001). This contributes to better cyclic freeze- thaw stability of the material, as well as its resistance against sulfates, chlorides, acids and alkalis. In accordance with the literature data, within the first 24 hours after the hydration begins, metakaolin microparticles serve essentially as microfiller to densify the structure of cement paste, as well as nucleation centers for the main product of cement hydration, which is (C-S-H). [9] The pozzolanic properties of metakaolin, i.e., its ability to interact with $\mathrm{Ca}(\mathrm{OH}) 2$ to form a C-S-H, which helps for further densification of the microstructure of cement paste, mortar or concrete, appear in the subsequent period ( 3 - 7 days on). Besides $\mathrm{C}-\mathrm{S}-\mathrm{H}$, the products formed by metakaolin and $\mathrm{Ca}(\mathrm{OH}) 2$ interacting are calcium aluminate hydrates $\mathrm{C} 4 \mathrm{AH} 13$ and $\mathrm{C} 2 \mathrm{ASH} 8$ (Stratlingite) and at higher temperature more than 60 degree C3AH6 (hydrogarnet) is formed.

The pozzolanic activity of metakaolin depends on the content and the structural features of its main constituent-metakaolinite, its particles fineness (specific surface area), the chemical nature and amount of impure components. [10] These characteristics of metakaolin are determined in turn by the composition of raw materials and processing parameters. Therefore, the varieties of metakaolin by different manufacturers may differ quite considerably in terms of pozzolanic activity. Thus, the study of the peculiarities of transformation of metakaolin being a part of cement paste is of a practical importance. This information is necessary for both interpreting the physical and mechanical properties of Portland cement materials supplemented with metakaolin and for estimating its optimal dosage. 
The in-depth study of the results of the research study of metakaolin and their further analysis using sophisticate equipment like TGA, DSC, SEM, XRD, XRF, FTIR clearly shows that adding very fine clayey particles (having micro-nano size and high surface area) to the cement matrix paste and mortars improves the microstructure of the hardened paste in the early days of hydration (as early as 1 day) by making it dense and homogeneous. This occurs as the micro fine particles which are highly reactive, provides nucleation sites for the freshly formed hydrates of cement that is CSH and makes it more homogenous and dense. At later stage when then the solution becomes alkaline enough due to the concentration of $\mathrm{Ca}++$ and $\mathrm{OH}$ - ions the silicates and aluminates reacts with the $\mathrm{CH}$ so formed and forms more $\mathrm{CSH}$ gel which is a strength giving compound. Thus, they remove the calcium hydroxide liberated from cement hydration which is detrimental to the concrete.

\section{CONCLUSION}

Researchers around the world studying the impact of various types of clays on the concrete properties have come to the conclusion that of all types of clay in the world, kaolinite is the best pozzolanic clay of all. As is seen above that the pozzolanic nature of metakaolin depends upon its process of calcinations which alters its physical characteristics such as the surface area, the particle size, the amorphousness. Thus, studying the effect of metakaolin on the strength and durability of concrete in light of these physical attributes making use of sophisticated instruments like XRD, XRF, EDXS, TGA, DSC, SEM would lead the industry to using the material in a more optimal, smart and intelligent way. A relation can be developed between the mechanical and transport properties of concrete and the physical characteristics of the material.

Its optimal and judicious usage in concrete can result in enhancing the performance of concrete and making Concrete - "A Sustainable Concrete", concrete which is More Economically viable, Socially Acceptable and Environmental friendly than the normal concrete.

\section{REFERENCES}

[1] S. Aiswarya, G. P. Arulraj, and C. Dilip, "A review on use of metakaolin in concrete," IRACST- Engineering Science and Technology Journal, vol. 3, no. 3, 2013.

[2] K. Rajasekhar and K Spandana, "Partial replacement of metakaolione in cement concrete," IJRSET, vol. 1, no. 4, 2015.

[3] C. Poon, L. Lam, S. C. Kou, Y. Wong, and R. Wong, "Rate of pozzolanic reaction of metakaolin in high-performance cement pastes," Cem. Concr. Res., vol. 31, pp. 1301-1306, 2001.

[4] C. S. Poon, S. C. Kou, and L. Lam, "Compressive strength, chloride diffusivity and pore structure of high performance metakaolin and silica fume concrete," Construction asd Building Materials, vol. 20, pp. 858-865, 2006.

[5] E. Badogiannis, G. Kakali, and S. Tsivilis, "Metakaolin as supplementary cementitious material optimization of kaolin to metakaolin conversion," Jopurnal of Thermal Analysis and Calorimetry, vol. 81, pp. 457-462, 2005.

[6] Wikipedia, "Metakaolin Kaolinite sources Forming metakaolin Adsorption properties," pp. 1-4, 2015.

[7] P. Lawrence, M. Cyr, and E. Ringot, "Mineral admixtures in mortars Effect of inert materials on short term hydration," Cement and Concrete Research, vol. 33, 2003.

[8] M. Frías, M. I. S. De Rojas, and J. Cabrera, "The effect that the pozzolanic reaction of metakaolin has on the heat evolution in metakaolin-cement mortars," vol. 30, pp. 209-216, 2000.

[9] S. Zhonghe, S. U. N. Tao, F. U. Zhiheng, and W. Guiming, "Dominant Factors on the Early Hydration of Metakaolin-Cement Paste," $J$. Wuhan Univ. Technol. Sci., pp. 849-852, 2010.

[10] S. Lucia and P. Politecnico, "Metakaolin as a pozzolanic microfiller for high performance mortars," Cem. Concr. Res., vol. 28, no. 6, pp. 803$809,1998$.

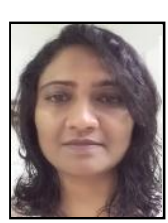

Sonal Shah was born in Ahmedabad on 12th Oct 1976 has completed her masters of technology in structural engineering and pursuing her $\mathrm{PhD}$ in applied mechanics Department of SVNIT, Surat. Area of research is concrete technology.

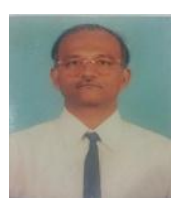

S. N. Desai was born in Surat, in 1953, is at present associate professor at Applied Mechanics Department of Sardar Vallabhbhai National Institute of Technology. Research area is Concrete Technology. 